\title{
Executive functioning in preschool children born very preterm: Relationship with early white matter pathology
}

\author{
JAMIE O. EDGIN, $, 1,2$ TERRIE E. INDER,, 3 PETER J. ANDERSON,, 5 KELLY M. HOOD, ${ }^{1}$ \\ CARON A.C. CLARK, ${ }^{1}$ AND LIANNE J. WOODWARD ${ }^{1}$ \\ ${ }^{1}$ Department of Psychology, University of Canterbury \& Van der Veer Institute for Parkinson's and Brain Research, \\ Christchurch, New Zealand \\ ${ }^{2}$ Department of Psychology, University of Arizona, Tucson, Arizona \\ ${ }^{3}$ Department of Pediatrics, Neurology, and Radiology, Washington University, St. Louis, Missouri \\ ${ }^{4}$ St. Louis Children's Hospital, St. Louis, Missouri \\ ${ }^{5}$ School of Behavioral Science, University of Melbourne, Murdoch Children's Research Institute, Melbourne, Australia \\ (Received August 8, 2006; Final Revision June 15, 2007; AcCePted June 17, 2007)
}

\begin{abstract}
Despite evidence for executive dysfunction in school-aged preterm children, less is known about the early development of these difficulties or their underlying neuropathology. This study used prospective longitudinal data from a regional cohort of 88 very preterm and 98 full-term comparison children to examine the executive functioning $(\mathrm{EF})$ of preschool children born very preterm. The relationship between the severity of neonatal cerebral white matter (WM) abnormalities on magnetic resonance imaging (MRI) at term equivalent and children's EF at ages two and four years (corrected age) was examined. At age four, very preterm children with WM abnormalities performed less well than full-term children on the Detour Reaching Box, a measure of behavioral inhibition and cognitive flexibility, even after controlling for child IQ, SES, and medical background. Examination of patterns of EF performance between the ages of 2 and 4 years showed that the performance of all groups improved with age. However, very preterm children with mild and moderate-severe WM abnormalities were characterized by higher rates of consistent performance impairments. These findings support the presence of early and persistent executive difficulties in preschool children born very preterm, and highlight the importance of white matter pathology in the development of executive impairments. (JINS, 2008, 14, 90-101.)
\end{abstract}

Keywords: Very low birth weight, Neurobehavioral manifestations, Infant premature, Brain injuries, Child preschool, Magnetic resonance imaging.

\section{INTRODUCTION}

Dramatic improvements in the survival of children born very preterm $(<33$ weeks gestation) and/or very low birth weight $(<1500$ grams) have been accompanied by growing concerns regarding these children's longer term developmental outcomes. Across development, very preterm children have been shown to be at high risk for cognitive impairment and educational under-achievement (Anderson et al., 2003; Bhutta et al., 2002; Horwood et al., 1998). Such findings highlight the need to better understand the

Correspondence and reprint requests to: Jamie Edgin, University of Arizona, Department of Psychology, 1503 E. University Blvd., Building 68, Tucson, AZ 85721. E-mail: jedgin@email.arizona.edu. specific neuropsychological impairments that place very preterm children at risk for cognitive difficulties.

One set of neuropsychological skills that has attracted considerable interest within the fields of developmental neuropsychology and child psychopathology is executive functions (EF). These skills refer to a set of processes necessary for purposeful, goal-directed behavior (Welsh \& Pennington, 1988). Several studies suggest that by school-age, very preterm children are characterized by a range of executive difficulties, including poor planning and problem solving, impaired working memory and disinhibition (Anderson et al., 2004; Luciana et al., 1999; Taylor et al., 2004, 2006). Importantly, these difficulties have been shown to predict later educational outcomes (e.g., mathematics; Assel et al., 2003). Table 1 provides an overview of previous studies of $\mathrm{EF}$ in preterm children. 
Table 1. Previous studies of executive functions in school-age and preschool children born preterm

\begin{tabular}{|c|c|c|c|c|}
\hline Study & $\begin{array}{l}\text { Age group } \\
\text { studied }\end{array}$ & $\begin{array}{l}\text { Gestation, } \\
\text { birthweight (range) }\end{array}$ & Executive function measures & $\begin{array}{c}\text { Effect sizes } \\
d\end{array}$ \\
\hline Taylor et al. $(2004)^{\mathrm{a}}$ & 16 years & 23-32 weeks & $\begin{array}{l}\text { CANTAB ID/ED } \\
\text { CANTAB Stockings of Cambridge*** } \\
\text { CANTAB Spatial Working Memory*** } \\
\text { CANTAB Rapid Visual Processing*** } \\
\text { Contingency Naming Efficiency } * * *\end{array}$ & $\begin{array}{l}.01, .50 \\
.35, .83 \\
.34,1.08 \\
.17, .72 \\
.50,1.20\end{array}$ \\
\hline Taylor et al. (2006) & 8 years & $<1000 \mathrm{~g}$ & NEPSY EF and Memory Composite*** & .73 \\
\hline Rushe et al. (2001) & $14-15$ years & $\begin{array}{l}<33 \text { weeks, } \\
\text { Mean gestation }=29.64 \\
S D=1.84\end{array}$ & $\begin{array}{l}\text { FAS Verbal Fluency*** } \\
\text { Trails B } \dagger \\
\text { Rey-Osterrieth Copy } \\
\text { Digit Span } \dagger\end{array}$ & $\begin{array}{r}.73 \\
.29 \\
-.20 \\
.17\end{array}$ \\
\hline $\begin{array}{l}\text { Anderson, Doyle, and } \\
\text { the VICS group (2004) }\end{array}$ & 8 years & $\begin{array}{l}\text { 23-28 weeks } \\
\& / \text { or }<1000 \text { grams }\end{array}$ & $\begin{array}{l}\text { Digit Span*** } \\
\text { Tower of London** } \\
\text { BRIEF global executive composite*** } \\
\text { Rey-Osterrieth Copy*** }\end{array}$ & $\begin{array}{l}.35 \\
.21 \\
.31 \\
.64\end{array}$ \\
\hline Luciana et al. (1999) & $7-9$ years & $24-39$ weeks & $\begin{array}{l}\text { CANTAB Spatial Working Memory*** } \\
\text { CANTAB Spatial Span** } \\
\text { CANTAB Tower of London* } \\
\text { CANTAB ID/ED }\end{array}$ & $\begin{array}{l}.79 \\
.56 \\
.52 \\
.07\end{array}$ \\
\hline $\begin{array}{l}\text { Bayless \& Stevenson } \\
\text { (2007) }\end{array}$ & $6-13$ years & 23-32 weeks & $\begin{array}{l}\text { TEA-Ch Selective Attention } \\
\text { TEA-Ch Set-shifting* } \\
\text { TEA-Ch Inhibitory Control* } \\
\text { CANTAB Spatial Working Memory }\end{array}$ & $\begin{array}{l}.92 \\
.53\end{array}$ \\
\hline Bohm et al. (2002) & $5-6$ years & 23-36 weeks & $\begin{array}{l}\text { Verbal fluency** } \\
\text { Selective attention* } \\
\text { Modified WCST } \\
\text { Color/Form Test** } \\
\text { Impulse control** }\end{array}$ & $\begin{array}{l}.42 \\
.27 \\
.06 \\
.53 \\
.33\end{array}$ \\
\hline Caravale et al. (2005) & $3-4$ years & $30-34$ weeks & $\begin{array}{l}\text { Visual search } * * * \\
\text { Spatial location memory test } * * *\end{array}$ & $\begin{array}{l}1.08 \\
1.1\end{array}$ \\
\hline Vicari et al. (2004) & $3-4$ years & 29-34 weeks & $\begin{array}{l}\text { Attention** } \\
\text { Spatial Working Memory-Delayed Recall*** } \\
\text { Spatial Working Memory-Location Recall** }\end{array}$ & $\begin{array}{r}.90 \\
1.29 \\
.84\end{array}$ \\
\hline Espy et al. (2002) & $2-3$ years & 28-36 weeks & $\begin{array}{l}\text { Delayed alteration** } \\
\text { Spatial reversal }\end{array}$ & $\begin{array}{l}.35 \\
.02\end{array}$ \\
\hline Ross et al. $(1996)^{b}$ & 2 years & $28-32$ weeks & $\begin{array}{l}\text { Invisible displacements* } \\
\text { Object Discrimination* }\end{array}$ & $\begin{array}{r}.85 \\
1.16\end{array}$ \\
\hline Woodward et al. (2005) & 2 years & 23-32 weeks & $\begin{array}{l}\text { MSML Task duration of training* } \\
\text { MSML trials to first retrieval } \\
\text { MSML trials discontinued or repeated* } \\
\text { MSML post switch performance* }\end{array}$ & $\begin{array}{l}.37 \\
.27 \\
.35 \\
.41\end{array}$ \\
\hline Matthews et al. (1996) & $28-60$ weeks & $34-36$ weeks & $\begin{array}{l}\text { AB Task } \\
\text { Barrier detour } \\
\text { Means-ends Tasks }\end{array}$ & $\begin{array}{l}\text { No means } \\
\text { reported }\end{array}$ \\
\hline Ross et al. (1992) & 10 months & $28-32$ weeks & AB Task* & $\begin{array}{c}\text { No means } \\
\text { reported }\end{array}$ \\
\hline
\end{tabular}

$\dagger p<.10, * p<.05, * * p<.01, * * * p<.001$; a: listed effect sizes correspond to the comparison between $750-1499 \mathrm{~g}$ versus term and $<750 \mathrm{~g}$ versus term respectively; b: effects were found only in preterm children with IVH; Abbreviations, CANTAB: Cambridge Neuropsychological Test Automated Battery; ID/ED: Intra-dimensional/Extra-dimensional set-shifting; FAS: letter fluency; BRIEF: Behavior Rating Inventory of Executive Function; WCST: Wisconsin Card Sorting Task, MSML: Multi-Search Multi-Location. 
Although these studies provide strong evidence that children born very preterm are characterized by executive difficulties during middle childhood and early adolescence, the extent of these difficulties in early childhood is less clear. Specifically, study findings remain mixed, with some studies suggesting intact EF skills [e.g., working memory (Matthews et al., 1996); shifting set (Espy et al., 2002)], and others demonstrating performance impairments, especially in working memory (Espy et al., 2002; Ross et al., 1996; Ross et al., 1992; Vicari et al., 2004; Woodward et al., 2005). Because several of these studies were based on nonrepresentative or low risk samples (Espy et al., 2002; Matthews et al., 1996; Vicari et al., 2004), further research is needed to clarify the pattern of these difficulties in high risk preterm infants during early childhood.

In addition, our understanding of the medical and socialenvironmental factors associated with EF difficulties in this population is limited. Effect sizes for differences in EF are typically higher for children born extremely small $(<750$ grams) or extremely preterm ( $<28$ weeks). This suggests that immaturity may contribute to the development of executive difficulties, although the reasons for this increased risk are unclear. Furthermore, few studies have taken into account between-group differences in social risk or IQ, making it difficult to ascertain whether EF difficulties represent a primary impairment or are secondary to other factors.

Further, it is clearly important to understand the neuropathological mechanisms that may contribute to very preterm children's EF difficulties. Injury to the cerebral white matter (WM) is the most common neuropathology found in the preterm infant and forms a spectrum known as periventricular leukomalacia (PVL), with a severe form involving the formation of cystic lesions as well as diffuse WM loss (Perlman, 1998). Recent MRI studies reveal that an even larger number of very preterm infants are characterized by less severe and more diffuse WM abnormalities. For example, in our cohort of infants born very preterm, high rates of mild $(51 \%)$ and moderate-severe (20\%) WM abnormalities were evident by term equivalent age. These abnormalities included focal signal abnormalities, ventricular dilatation, thinning of the corpus callosum, WM volume loss and delayed myelination (Inder et al., 2003; Woodward et al., 2006; Woodward et al., 2004). The presence of such WM abnormalities may impact subsequent cortical development and neural connectivity, particularly within prefrontal circuits (Luciana, 2003). Neonatal WM abnormalities on qualitative MRI have been shown to be associated with global reductions in cortical gray matter volumes among very preterm infants by term equivalent age (Inder et al., 2005; Inder et al., 2003). Thus, early WM abnormalities may have cascading effects on cerebral development, which may also compromise executive functioning.

Many previous studies of EF in very preterm children have lacked neuroimaging data, relying instead on cranial ultrasound or clinical risk factors correlated with brain injury to infer possible linkages between cerebral injury and EF (Curtis et al., 2002; Taylor et al., 2004). In our cohort of very preterm infants we demonstrated a relationship between MRI-defined WM abnormalities at term age and later working memory impairment at age 2 years (Woodward et al., 2005). Such studies are likely to improve our understanding of the neural mechanisms underlying the cognitive deficits common to this population.

Finally, in defining the nature of executive deficits in very preterm children and their underlying neuropathology, it is also important to understand how these functions develop during early childhood. Research findings have been inconsistent in this regard (Luciana, 2003), with some investigators proposing that very preterm children may "catch-up" with age because of neural plasticity and functional recovery (Ment et al., 2003). In contrast, others suggest that persistent impairments are more likely, with some children potentially showing greater impairment with increasing age (Taylor et al., 2004). To date, only one longitudinal study has examined the development of executive processes in preschool children born very preterm (Ross et al., 1996). They found that between 10 months and 2 years, preterm children with intraventricular hemorrhage (IVH) made fewer developmental gains in EF than their preterm peers without IVH. Although previous studies are suggestive of persistent executive impairments, further longitudinal evaluation is important to help define the nature and course of these impairments. It is also important to note that whereas Ross et al. (1996) suggests that brain injury may contribute to persistent EF impairment, developmental change in this domain has not yet been related to more sensitive measurements of brain abnormalities, such as MRI estimates of WM injury.

In summary, a number of issues relating to the development of EF in very preterm children require further research and clarification. First, few neuropsychological studies to date have included sensitive neuroimaging techniques, such as MRI, and as a consequence, little is known about the neuropathological mechanisms relating to executive deficits. Second, research examining the early development of executive difficulties is scarce. Thus, little is known about when these problems emerge or how they evolve across early childhood. Accordingly, this paper extends on our previous study of EF at two years (Woodward et al., 2005), to address these important issues. Specifically, the study aims to:

1. Describe the performance of a highly representative group of very preterm children with no, mild and moderatesevere WM abnormalities detected on MRI at term equivalent, and a comparison group of full-term children on a measure of executive functioning administered at age 4 years (corrected).

2. Examine the extent to which differences in performance across the four study groups persisted after statistical adjustment for child IQ, family socioeconomic status, and a range of antecedent medical risk factors. The reasons for controlling for these factors were twofold: first 
to examine the possibility that executive function was selectively impaired (i.e., more affected than would be predicted by children's general cognitive abilities), and second to determine if these impairments were related to WM abnormality as opposed to associated medical complications.

3. Describe the development of executive function in very preterm children with varying levels of neonatal WM abnormality and full-term children from two to four years, and in particular, examine the continuity and change of children's performance over this developmental period.

We hypothesized that very preterm children would perform less well on the EF task at four years, even after controlling for potentially important background factors. Further, given our earlier finding of a link between WM abnormality and working memory impairment at age two years, we expected the severity of WM abnormality would be related to EF at four years. In line with previous longitudinal studies, we also anticipated that very preterm children with moderate to severe WM abnormalities would be characterized by consistently higher rates of EF impairment at two and four years than very preterm children without WM abnormalities and full-term children.

\section{METHODS}

\section{Participants}

\section{Very preterm group}

This group drawn from a regional cohort of 100 children born prior to 33 weeks gestation or under 1500 grams, and who were admitted consecutively to a level III Neonatal Intensive Care Unit (NICU) at Christchurch Women's Hospital, New Zealand from November 1998 to December 2000. Exclusion criteria included congenital abnormalities (e.g., Down syndrome) and non-English speaking parents. During this time period, 119 preterm infants met study criteria. There were 10 deaths. Of the remaining eligible infants during this period, 92\% were recruited (i.e., 4 missed, 5 refusals, total $n=100$ ).

Children in the very preterm group were assessed throughout the perinatal period, at term, and at one, two, and four years corrected age using a combination of measures, including MR imaging, medical records, parent interviews, and neuropsychological assessments. Of the 100 infants recruited following admission to the NICU, 93 participated in the two-year-old assessment and 96 participated in the assessment at four years. The two-year retention rate $(93 \%)$ included three children lost to follow-up, three deaths, and one child living abroad. At four years, one child from the original cohort was lost to follow-up and there were three deaths (i.e., $96 \%$ retention). No children in the very preterm group met diagnostic criteria for autism or seizure disorders by age four. Two children were unable to complete the cognitive and executive measures due to blindness $(n=1)$ or severe cerebral palsy $(n=1)$. Data from four additional children were excluded because of late completion of the assessment at four years, resulting in $n=90$ at four years. Children were assessed within two weeks of their expected date of delivery (expected birthday) for each time point. In order to maintain consistency across the two assessment points, children were assessed at their corrected age, providing a more conservative test of between group differences. Previous studies have suggested that correcting for gestational age at birth until 8.5 years in very preterm children results in scores with greater predictive utility (Rickards et al., 1989).

\section{Full-term group}

The full-term group was recruited at two years of age and consisted of 104 full-term children born $\geq 37$ weeks' gestation. Full-term children were identified from hospital birth records ( $n=7200$ total births) by selecting a same-sex child born two births before or two births after the delivery of each preterm child. These children were free from congenital abnormalities and birth complications such as growth restriction. Non-English speaking families were excluded. One child with autism was excluded from the control sample prior to the four-year assessment. We over-recruited in this group to compensate for potential attrition, resulting in a total of 103 controls. The recruitment rate was $62 \%$. Reasons for non-participation included: untraced (47\%); moved overseas (12.5\%); refused (12.5\%); and agreed but not seen within the assessment window at the initial two years assessment (24 months \pm 2 weeks) because of illness or family circumstances $(28 \%)$. Children who were recruited did not differ from those who were not recruited in terms of infant birth weight, gestation, gender, socioeconomic status, family type, or Maori ethnicity. Retention of the term control sample to age four was $96 \%(n=99)$, with four children lost to follow-up. An additional 1 child was excluded because of non-completion of the EF measure at four years, resulting in a total of 98 children in the full-term group.

\section{Procedures and Measures}

In addition to comprehensive medical data collected throughout the perinatal period, all very preterm children underwent an MRI at term equivalent. Equivalent medical data was collected retrospectively from the medical records of all full-term children, however MRI data was not collected. At two and four years corrected age, all children completed a neuropsychological assessment including EF measures. Parental interviews were administered to obtain information about family social background and experiences. All assessment procedures were in compliance with the regulations of the University of Canterbury and were approved by the Canterbury Regional Ethics Committee.

\section{Cerebral white matter abnormality at term}

At term equivalent age (39-41 weeks gestation), all very preterm infants underwent an MRI scan. Prior to imaging, 
infants were fed, wrapped and placed unsedated in a Vac Fix bean bag. MR imaging was performed using a 1.5 Tesla General Electric Signa System (GE-Medical Systems, Milwaukee, WI). For the acquisition of primary MRI data, two different imaging modes were applied. These included: (a) a 3-dimensional Fourier transform spoiled gradient recalled (SPGR) sequence (1.5 mm coronal slices, flip angle 45 degrees, repetition time $35 \mathrm{~ms}$, echo-time $5 \mathrm{~ms}$, field of view $18 \mathrm{~cm}$, matrix $256 \times 256)$ and (b) a double echo (proton density and T2-weighted)-spin echo sequence (DE) (3-mm axial slices, repetition time $3000 \mathrm{~ms}$, echo times 36 and $162 \mathrm{~ms}$, field of view $18 \mathrm{~cm}$, matrix $256 \times 256$, interleaved acquisition). The voxel (volume of the pixel) dimensions were $0.7 \times 0.7 \times 1.5 \mathrm{~mm}$ for the SPGR acquisition, and $0.7 \times 0.7 \times 3 \mathrm{~mm}$ for the spin echo acquisition.

All scans were scored independently by a pediatric neuroradiologist and neurologist (95\% inter-rater agreement). Raters were blind to infant perinatal history. The scoring system for WM abnormality was adapted from previously published systems (Valkama et al., 2000) and has been described previously (Inder et al., 2003; Woodward et al., 2004). Table 2 provides a detailed description of the criteria for these ratings. WM was graded with a score between one and three for five variables: WM signal abnormality (shortening T1-weighted imaging), reduction in WM volume, cystic abnormality, lateral ventricular size, and thinning of the corpus callosum and delayed myelination. Term equivalent MRI scans were performed on 99 of the 100 original participants in the preterm group, and WM abnormality ratings were available on scans for 88 of the 90 preterm children who had complete behavioral data at age four. On the basis of their total scores (range 5-15), preterm infants were then divided into four groups: (1) no WM abnormality (score 5-6, $n=22$ ); (2) mild (score 7-9, $n=49$ ); (3) moderate (score $10-12, n=14$ ) and (4) severe WM abnormality (score $13-15, n=3)$. Given the small numbers of children with severe, typically cystic WM abnormalities $(n=3)$, the moderate and severe groups were combined for analyses.

\section{Assessment at age two years (corrected)}

A modified three-step Multi-Search Multi-Location (MSML) task was the EF measure administered at two years (Wood- ward et al., 2005; Zelazo et al., 1998). This task required children to track the location of a hidden reward and inhibit responses to a previously rewarded location, thus involving working memory and inhibitory control (Diamond, 1990; Espy et al., 2001, 1999).

During this task the researcher introduced a wooden box that contained three shapes attached to pouches on a string. The box had a plexiglass front window. The shapes were placed near the child while the pouches remained behind the window. First, children practiced retrieving a candy placed in a pouch in the uncovered box. Then, in full view of the child, the experimenter placed a candy in one of the pouches attached to a different shape, announced its location, and placed a wooden occluder over the view into the box and a foam barrier over the shape stimuli. The researcher then invited the child to retrieve the candy. This procedure was repeated until the child successfully retrieved the candy three times consecutively. For the postswitch trial, the same process was repeated, except the candy was placed in a pouch attached to the last differing shape. Performance on this task was coded as pass/fail. The child failed this test if he or she failed to locate the candy on the single postswitch trial.

\section{Assessment at age four years (corrected)}

At four years (corrected age), EF was assessed using a modified version of the Detour Reaching Box (DRB) Task (Hughes et al., 1998; Hughes \& Russell, 1993). This task provides a measure of inhibitory control (i.e., the ability to inhibit a prepotent, salient response) and the ability to switch effectively from a previously reinforced rule. Therefore, the executive processing demands of this task were similar to the MSML task administered at two years.

The testing apparatus consisted of an aluminum box with a centrally positioned hole. Mounted inside the box was a platform on which a ball was placed. Physically reaching inside the box to the retrieve the ball caused a trapdoor to open and the ball to drop out of sight. Two lights were located on the front face of the box, one yellow and one green. When the yellow light on the top right face of the box was activated, a knob positioned on the right side of the box could be turned to retrieve the ball ("knob-route"). Alternatively, when the green light was on (i.e., located on the

Table 2. Qualitative ratings of white matter abnormality

\begin{tabular}{|c|c|c|c|}
\hline & Score 1 & Score 2 & Score 3 \\
\hline White matter signal abnormality & Nil & Focal (1 region only) & $\geqq 2$ regions (e.g., parieto-occipital) \\
\hline Reduction in white matter volume & Normal & Mild-moderate loss & Diffuse loss \\
\hline Cystic abnormality & Nil & Focal cystic change & Extensive white matter cystic changes \\
\hline Lateral ventricle size & Normal & Mild-moderate dilation & Marked ventricular dilation \\
\hline Corpus callosum and myelination & $\begin{array}{c}\text { Normal or isolated } \\
\text { partial thinning }\end{array}$ & Marked thinning & $\begin{array}{l}\text { Marked thinning of the corpus callosum } \\
\text { and significant delay in myelination } \\
\text { including the PLIC* }\end{array}$ \\
\hline
\end{tabular}

Note. Each of the five domains of white matter development was assigned a score ranging from 1-3, thus resulting in a total white matter score on a scale ranging from 5-15.

* PLIC: posterior limb of the internal capsule. 
left hand face), a switch on the left side of the box could be pushed, allowing the child to retrieve the ball directly from the platform ("switch-route").

The task procedure involved three phases: two phases in which the child learned each search strategy (i.e., the knob and switch routes) followed by a final phase in which the child was required to alternate between these rules. Each assessment began with a demonstration that the ball could not be retrieved via the direct route. After this preliminary demonstration, each child was then shown the yellow light, followed by the experimenter stating "I'll show you the trick for how to get the ball out when the yellow light is on. Let's see what happens when I turn this knob." The child was then asked to attempt to retrieve the ball in the same way. To pass this phase of the task, children were required to correctly retrieve the ball via the knob route on three consecutive trials. A trial started when the ball was placed on the platform, and the light corresponding to the trial was illuminated. The children were then oriented to the task, and asked, "How do we get the ball when the yellow light is on?" The trial was completed after the child's attempt to retrieve the ball (i.e., either correct or incorrect). In the knob route phase, children failed the trial if they directly reached into the box, an indication of poor inhibitory control. A maximum of 15 trials were allowed to reach the criterion of three consecutive correct responses.

After meeting criterion on the knob-route trials, the second phase of "switch-route" trials commenced. During this phase, the child was shown that the knob-route was no longer working and that the ball still could not be retrieved by reaching directly into the box. The experimenter then said "I'll show you the trick for getting the ball out when the green light is on" and modeled the new switch route procedure, which required the child to hold a switch while simultaneously reaching directly into the box to retrieve the ball. Trials then commenced in a similar fashion to the knob phase. To reach criterion on this phase of the task, children needed to use the switch-route correctly on three consecutive trials. The task was terminated at this point if children failed to achieve criterion within 15 trials.

In the final phase of the task, the procedure was extended to increase the executive demands. This phase included eight additional tests in which the knob-route and switch-route rules were alternated (i.e., green light, yellow light, green, green, yellow, etc). Children were oriented to the rule required for each of the tests by the experimenter pointing out the color of the light. In each of the eight final tests, children were allowed a maximum of eight attempts to use the correct rule.

For each phase of the task, the total number of trials and the types of errors were recorded. Similar to Hughes \& Russell (1993), we recorded the number of perseverative errors during the postswitch and alternating phases. These errors included direct reaches or the use of a rule indicated by the opposite light (i.e., trying to use the knob when a green light was on). In total, the measures of interest on this task were the number of trials to reach criterion in the first two phases (ranging from 3-15 in the knob and switch route phases), the percentage of children successfully reaching criterion on each phase, and the number of perseverative errors during the second and alternating phases. For assessment of the continuity of measures, we also scored this test as pass/fail. To pass this measure, the child had to meet criterion on the first two phases and also had to use the rules effectively on the alternating phase (i.e., obtained an average of 1 error or less per alternating test).

At four years, IQ was estimated using a short-form of the Wechsler Preschool and Primary Scales of IntelligenceRevised (WPPSI-R, Wechsler, 1989) comprising two Verbal Scale subtests (Comprehension, Arithmetic) and two Performance Scale subtests (Picture Completion, Block Design). Reliability coefficients for this short form of the WPPSI-R range from .91 to .94 and correlations with fullscale IQ scores range from .89 to .92 (LoBello, 1991).

\section{Statistical Analysis}

For all statistical analyses, children born full-term were compared with three groups of children born very preterm divided on the basis of the severity of cerebral WM abnormalities. These groups included very preterm children with no $(n=22)$, mild $(n=49)$, and moderate to severe $(n=17)$ WM abnormalities.

Data analysis was completed in three steps. First, the clinical and family characteristics of all study children were described. Second, group differences on the DRB task at age 4 years were examined with and without statistical adjustment for background variables differing between the groups (i.e., IQ, SES, clinical risk). These analyses were undertaken using either one-way ANOVA for continuously distributed variables or the chi-squared test of independence for dichotomous variables, followed by ANCOVA or logistic regression when adjusting for background variables. Posthoc tests were also conducted with LSD multiple comparisons in ANOVA and individual chi-square tests. Finally, general estimating equations (GEE) was used to examine the effects of the independent variable (i.e., WM abnormality group: controls, no, mild, and moderate-severe) on fluctuations in the dependent variable (i.e., EF task failure) over time, taking into account correlations between repeated observations (Zeger \& Liang, 1986, 1992). Within this analysis simple (group, age) and interaction (group $\times$ age) effects were assessed. An alpha level of .05 was used to detect significance for all analyses.

\section{RESULTS}

\section{Clinical and Background Characteristics}

Table 3 describes the clinical and family background characteristics of full-term and very preterm children with no, mild, and moderate-severe WM abnormalities. Results revealed clear differences in gestational age across the four groups ( $p<.001$ ), whereas birth weight was similar across 
Table 3. Infant clinical and family social background characteristics of children born at term and children born very preterm with no, mild, and moderate-severe white matter abnormalities

\begin{tabular}{|c|c|c|c|c|c|c|c|}
\hline \multirow[b]{2}{*}{ Measure } & \multirow[b]{2}{*}{$\begin{array}{l}\text { Full-term } \\
\text { controls } \\
(N=98)\end{array}$} & \multicolumn{3}{|c|}{$\begin{array}{c}\text { Very preterm- } \\
\text { level of white matter abnormality }\end{array}$} & \multirow[b]{2}{*}{$F / \chi^{2}$} & \multirow[b]{2}{*}{$p$} & \multirow[b]{2}{*}{$\begin{array}{l}\text { Between- } \\
\text { group } \\
\text { differences }\end{array}$} \\
\hline & & $\begin{array}{c}\text { None } \\
(N=22)\end{array}$ & $\begin{array}{c}\text { Mild } \\
(N=49)\end{array}$ & $\begin{array}{l}\text { Mod- } \\
\text { severe } \\
(N=17)\end{array}$ & & & \\
\hline \multicolumn{8}{|l|}{ Clinical characteristics } \\
\hline Mean (SD) Gestation & $\begin{array}{l}39.58 \\
(1.10)\end{array}$ & $\begin{array}{l}29.64 \\
(1.79)\end{array}$ & $\begin{array}{l}27.94 \\
(2.17)\end{array}$ & $\begin{array}{l}26.65 \\
(2.62)\end{array}$ & 719.53 & $<.001$ & $\mathrm{FT}>\mathrm{N}>\mathrm{M}>\mathrm{M}-\mathrm{S}$ \\
\hline Mean (SD) Birth weight & $\begin{array}{l}3581.44 \\
(401.80)\end{array}$ & $\begin{array}{l}1214.32 \\
(246.08)\end{array}$ & $\begin{array}{l}1068.57 \\
(307.74)\end{array}$ & $\begin{array}{l}1057.59 \\
(350.92)\end{array}$ & 737.90 & $<.001$ & $\mathrm{FT}>\mathrm{N}, \mathrm{M}, \mathrm{M}-\mathrm{S}$ \\
\hline$\%$ Male & 53.1 & 50.0 & 51.0 & 58.8 & .38 & .94 & - \\
\hline$\%$ Singleton births & 98.0 & 68.2 & 67.3 & 64.7 & 31.99 & $<.001$ & $\mathrm{FT}>\mathrm{N}, \mathrm{M}, \mathrm{M}-\mathrm{S}$ \\
\hline$\%$ Intrauterine growth restriction* & - & 9.1 & 10.2 & 0.0 & 1.85 & .40 & - \\
\hline $\begin{array}{c}\text { \% Chronic lung disease (oxygen } \\
\text { requirement at } 36 \text { weeks) }\end{array}$ & - & 18.2 & 28.6 & 43.8 & 2.96 & .23 & - \\
\hline$\%$ Proven sepsis (infection) & - & 9.5 & 30.6 & 62.5 & 11.87 & .003 & $\mathrm{~N}<\mathrm{M}<\mathrm{M}-\mathrm{S}$ \\
\hline $\begin{array}{l}\% \text { Intraventricular hemorrhage } \\
\text { grade } 3 \text { or } 4 * *\end{array}$ & - & 0.0 & $\begin{array}{c}4.1 \\
(n=2)\end{array}$ & $\begin{array}{c}12.5 \\
(n=2)\end{array}$ & 6.45 & .04 & $\mathrm{~N}, \mathrm{M}<\mathrm{M}-\mathrm{S}$ \\
\hline \multicolumn{8}{|l|}{ Social Background Factors } \\
\hline Mean (SD) Maternal age (birth) & $\begin{array}{l}30.85 \\
(4.59)\end{array}$ & $\begin{array}{l}29.86 \\
(5.99)\end{array}$ & $\begin{array}{l}31.27 \\
(4.80)\end{array}$ & $\begin{array}{l}30.19 \\
(6.15)\end{array}$ & .48 & .70 & - \\
\hline$\%$ Mothers left school between & & & & & & & \\
\hline 13-16 years (at child's birth) & 18.9 & 40.0 & 38.8 & 43.8 & 9.82 & .02 & $\mathrm{FT}<\mathrm{N}, \mathrm{M}, \mathrm{M}-\mathrm{S}$ \\
\hline $\begin{array}{l}\% \text { Un-/semi-skilled socio-economic } \\
\text { status*** (2 years) }\end{array}$ & 11.6 & 35.0 & 36.7 & 43.8 & 17.19 & .001 & $\mathrm{FT}<\mathrm{N}, \mathrm{M}, \mathrm{M}-\mathrm{S}$ \\
\hline $\begin{array}{l}\% \text { Family income }<\$ 25,000 \\
\text { (at } 2 \text { years) }\end{array}$ & 18.5 & 20.0 & 29.8 & 12.5 & 3.23 & .36 & - \\
\hline $\begin{array}{l}\text { Standardized Cognitive Outcome } \\
\text { Mean (SD) WPSSI-R full-scale IQ } \\
\text { (4years) }\end{array}$ & $\begin{array}{l}104.85 \\
(12.45)\end{array}$ & $\begin{array}{l}104.36 \\
(11.22)\end{array}$ & $\begin{array}{c}96.12 \\
(11.95)\end{array}$ & $\begin{array}{c}82.47 \\
(13.57)\end{array}$ & 19.05 & $<.001$ & $\mathrm{FT}, \mathrm{N}>\mathrm{M}>\mathrm{M}-\mathrm{S}$ \\
\hline
\end{tabular}

+ Group differences significant $p<.05$.

*IUGR $-\mathrm{z}$-score $>2$ SD below weight for gestational age.

**IVH based on Papile classification.

*** Socioeconomic status defined according to Elley \& Irving (2003).

FT, Full-term children; N, No WM abnormality; M, Moderate WM abnormality; M-S, Moderate-severe WM abnormality.

the three preterm groups, but differed significantly from full-term children $(p<.001)$. Each preterm group had a similar proportion of singleton births, but the proportion was higher in controls $(p<.001)$. No significant gender differences were found. Preterm children also did not vary with respect to rates of intrauterine growth restriction (i.e., small for gestational age) or chronic lung disease (i.e., oxygen therapy at 36 weeks). However, very preterm children with less severe WM abnormalities were less likely to have been exposed to infection $(p<.05)$. Further, the risk of grade III/IV intraventricular hemorrhage on cranial ultrasound was significantly higher in the moderate-severe abnormality group, while the other preterm groups had equivalent rates $(p<.05)$.

With regard to social background factors, mothers from each preterm group tended to leave school earlier $(<16$ years) than mothers of full-term children $(p<.05)$. Levels of maternal educational achievement were similar across the three preterm groups, but higher in the full-term group $(p<.05)$. Similarly, the preterm groups were more likely to be of semi- or un-skilled socioeconomic status than the term group $(p<.01)$. No between group differences were found for maternal age or low family income.

At age four, very preterm children without WM abnormalities obtained similar IQ scores to their full-term peers. In contrast, very preterm children with mild and moderatesevere WM abnormalities performed less well than their term and preterm peers without WM abnormalities $(p<$ .001 ), with increasing severity of WM abnormalities being associated with poorer IQ test performance $(p<.001)$.

\section{Performance on the Detour Reaching Box at Age Four Years}

Table 4 describes the performance of very preterm children with no, mild and moderate-severe WM abnormalities and 
Table 4. Performance of full-term controls and preterm children with no, mild, and moderate-severe white matter abnormalities on the detour reaching box task at age 4 years

\begin{tabular}{|c|c|c|c|c|c|c|c|}
\hline \multirow[b]{2}{*}{ Measure } & \multirow[b]{2}{*}{$\begin{array}{l}\text { Full-term } \\
\text { controls } \\
(N=98)\end{array}$} & \multicolumn{3}{|c|}{$\begin{array}{c}\text { Very preterm- } \\
\text { severity of white matter abnormalities }\end{array}$} & \multirow[b]{2}{*}{$F / \chi^{2}$} & \multirow[b]{2}{*}{$p$} & \multirow[b]{2}{*}{$\begin{array}{l}\text { Adjusted } \\
p^{\mathrm{a}}\end{array}$} \\
\hline & & $\begin{array}{c}\text { None } \\
(N=22)\end{array}$ & $\begin{array}{c}\text { Mild } \\
(N=49)\end{array}$ & $\begin{array}{c}\text { Mod- } \\
\text { severe } \\
(N=17)\end{array}$ & & & \\
\hline \multicolumn{8}{|l|}{ Knob Phase Trials (Preswitch) } \\
\hline Mean (SD) Trials to meet criterion & $3.13(.49)$ & $3.23(.87)$ & $3.90(2.67)$ & $4.06(1.84)$ & 3.68 & $.01 *$ & .05 \\
\hline$\%$ Children reaching criterion & 98.0 & 100.0 & 100.0 & 94.1 & 3.23 & .36 & .99 \\
\hline \multicolumn{8}{|l|}{ Switch Phase Trials (Postswitch) } \\
\hline Mean (SD) Trials to meet criterion & $6.01(3.63)$ & $5.53(3.02)$ & $6.65(4.28)$ & $6.09(3.14)$ & .42 & .74 & .48 \\
\hline Mean (SD) Proportion of perseverative & & & & & & & \\
\hline errors & $.18(.25)$ & $.15(.20)$ & $.20(.22)$ & $.24(.27)$ & .48 & 69 & .54 \\
\hline$\%$ Children reaching criterion & 86.8 & 77.3 & 78.7 & 73.3 & 2.89 & .41 & .82 \\
\hline \multicolumn{8}{|l|}{ Alternating Phase Trials } \\
\hline $\begin{array}{l}\text { Mean (SD) Perseverative errors per trial } \\
\text { completed }\end{array}$ & $.54(.61)$ & $.52(.46)$ & $1.12(1.20)$ & $1.51(.90)$ & 8.21 & $<.001 * *$ & .05 \\
\hline
\end{tabular}

Note. a: Adjusted for the significant background and clinical factors presented in Table 3, including gestation, singleton births, proven sepsis, IVH grade 3/4, SES, and WPSSI-R IQ using ANCOVA for continuous variables and logistic regression for dichotomous variables.

*Full-term $<$ Mild WM Abnormalities, Mod-Severe WM Abnormalities, $p<.05$.

**Full-term, No Abnormality $<$ Mild WM Abnormalities, Mod-Severe WM Abnormalities, $p<.05$.

full-term children on the DRB task at age four years. Results showed that the number of trials required to reach the preswitch (i.e., knob phase) criterion varied across the four groups $(p=.01)$. Posthoc tests revealed that preterm children with mild and moderate-severe WM abnormalities required more trials than full-term children to learn the initial rule $(p<.05)$. Nonetheless, despite requiring more trials to achieve task criterion, the very preterm groups were as likely to achieve the task criterion on this initial phase as their full-term peers (i.e., greater than $90 \%$ in all groups).

No significant differences were found in children's performance on postswitch (switch route) phase trials, including the number of trials to meet criterion and the proportion of perseverative errors. In total, $86 \%$ of controls and $73 \%$ to $78 \%$ of all preterm children achieved the criterion for the postswitch phase. Given that $32 \%$ of all very preterm and full-term children completed the task in the minimum number of trials needed to reach criterion (i.e., 3 trials) it is unlikely that the absence of group differences on this phase was caused by ceiling or floor effects.

As the task became more complex during the final alternating phase, the groups differed significantly in terms of the number of perseverative errors committed $(p<.001)$. Posthoc tests revealed that the mild and moderate-severe WM abnormality groups made significantly more perseverative errors during this task phase than full-term children and very preterm children without WM abnormalities ( $p<$ $.05)$. Furthermore, as seen in Table 4, these group differences remained significant after statistical control for background and clinical factors shown to correlate with prematurity and WM abnormality severity in Table 3, including gestation, singleton births, proven sepsis, IVH grade $3 / 4$, SES, and IQ.

\section{Continuity and Change in Executive Functioning at Two and Four Years}

Figure 1 shows the proportion of children in each group who were unable to achieve the pass criterion for the EF task administered at two and years of age, as well as the proportion of children failing at both age points. Inspection of the figure shows that across all four groups, rates of task failure decreased with age. Nevertheless, failure rates were consistently higher among very preterm children with mild and moderate-severe WM abnormalities than children born either full term or preterm without WM abnormalities. These differences were particularly noticeable in the rates of consistent failure at ages two and four (i.e., mild WM abnormality: $38.8 \%$, moderate severe WM abnormality: $68.8 \%$ vs. controls: $21.6 \%$ and no WM abnormality: $10 \%$ ).

These conclusions were supported by a GEE logistic regression model fitted to the joint failure rate data for the four groups across the two ages. This analysis revealed a significant age effect $\left(\chi^{2}(1)=13.35 ; p<.001\right)$, reflecting the fact that failure rates were lower at age four than at age two and a significant WM group effect $\left(\chi^{2}(3)=21.21 ; p<\right.$ .0001) reflecting the higher failure rates in the mild and moderate-severe WM groups. However, there was no significant age by group interaction $\left(\chi^{2}(3)=0.32 ; p=.96\right)$, suggesting that the change in failure rates from age two to age four years was not significantly different between groups. Estimates of effect size (odds ratios) derived from the fitted model showed that, across the two time points, the moderatesevere WM group had odds of EF task failure 6.4 times (95\% CI 2.4-16.9; $p<.0001)$ greater than for full-term controls. Averaged across two and four years, the odds of failure for the group with mild WM abnormalities were 


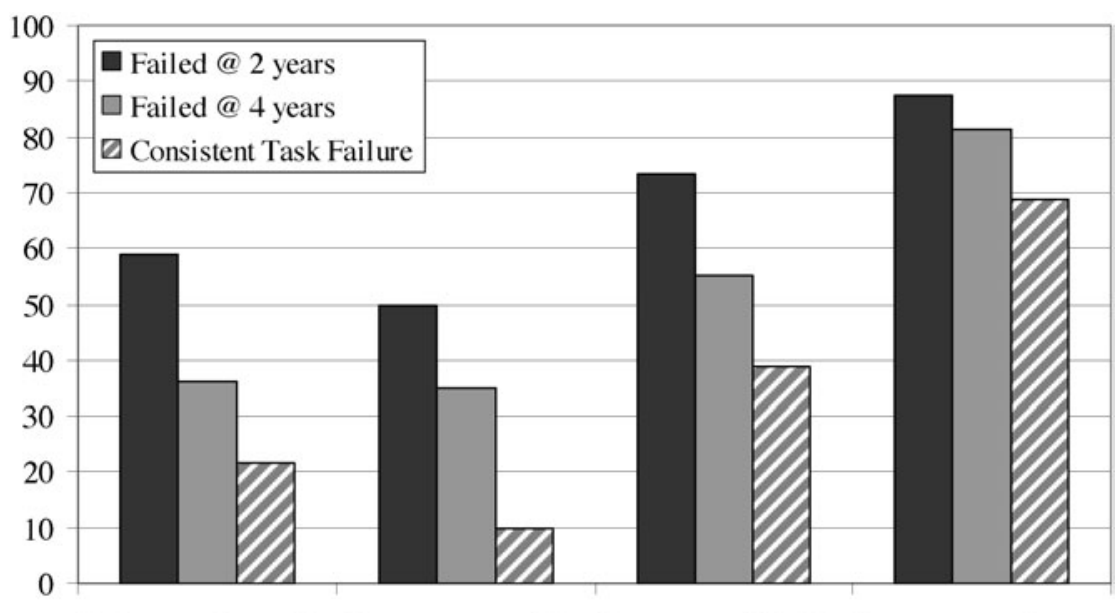

Full-term Control (n Preterm- no white Preterm- mild white Preterm- moderate=97) matter abnormality matter abnormality severe white matter $(\mathrm{n}=20) \quad(\mathrm{n}=49)$ abnormality $(\mathrm{n}=$

16)

Fig. 1. EF Task failure rates at ages two and four years old for children born full-term and children born very preterm with no, mild, and moderate-severe WM abnormalities.

Note: One full-term child and three very preterm children assessed at four years did not complete the assessment at two years.

somewhat lower but still differed significantly from fullterm children $(\mathrm{OR}=2.1 ; 95 \%$ CI $1.3-3.4 ; p<.005)$. However, the failure rates for the no WM abnormality group were not significantly different from controls $(\mathrm{OR}=0.8$; $95 \%$ CI $0.4-1.6 ; p=.55)$. These findings reveal the presence of persistent EF deficits in very preterm children with WM abnormalities detected on term MRI.

\section{DISCUSSION}

Drawing on prospective longitudinal data from a regional cohort of very preterm children, this study examined the early development of EF in this high risk population. In addition, this study assessed the relationship between cerebral WM abnormalities detected on MRI at term equivalent and subsequent executive impairments. Very preterm children with WM abnormalities experienced greater executive difficulties than full-term controls based on their performance on the modified DRB task at four years. Specifically, very preterm children with mild to moderate-severe WM abnormalities showed poorer behavioral inhibition as displayed by the increased number of trials required to learn the initial rule of the task (i.e., knob route) because of their tendency to reach directly into the box. Children with WM abnormalities were also more likely to make errors during the alternating phase of the task, which required children to switch between the knob and switch rules, suggesting very preterm children with WM abnormalities experience greater difficulty switching rapidly between different response sets. No difficulties were evident on the switch phase of the task for any of the very preterm groups. Thus, by age four, very preterm children with WM abnormalities appear able to inhibit a prepotent response, but experience cognitive inflexibility in that they have a tendency to make errors when alternating between contrasting rules. This specific pattern of impairment emphasizes the value of using experimental measures with differing levels of complexity to help specify difficulties under various levels of cognitive demand.

The differences in executive function at four years in the children with WM abnormalities persisted even after statistical control for intellectual ability, social background, and perinatal characteristics. Therefore, specific impairments in executive function can be demonstrated at a young age in children born very preterm. Furthermore, WM abnormality was more strongly related to executive impairment than other medical background factors such as gestational age, proven sepsis, IVH grade $3 / 4$, and multiple births. This finding is consistent with other recent findings demonstrating the predictive validity of MRI (Woodward et al., 2006). In this study, qualitative ratings of moderate-severe WM abnormalities made a significant independent contribution to neurodevelopmental outcomes over and above other neonatal measures.

Whereas the current developmental findings should be interpreted cautiously given that different measures were administered at two and four years, the results suggest that rate of EF impairment in very preterm children remains stable between age two and four years compared to fullterm children. Specifically, very preterm children without cerebral WM abnormalities on term MRI were characterized by similar EF performance as their full-term peers across both time points. In contrast, children with mild and moderate-severe WM abnormalities had higher rates of EF impairment than full-term children at two and four years. 
These findings suggest that very preterm children with WM abnormalities are characterized by persistent difficulties in EF in early childhood, with little evidence of developmental catch-up with age in the preschool years. Thus, our current findings expand on the findings of Ross et al. (1996) who found fewer gains in EF skills in preterm toddlers with brain injury (i.e., IVH). Whereas we did find evidence for persistent deficits, we found no evidence for differing rates of developmental change across the two timepoints. Our failure to detect group differences in rates of change may have reflected the use of differing measures at each time point, limiting our sensitivity to change. Another possibly is that differing rates of development could emerge in the preterm groups with WM abnormality as EF measures become more demanding in later childhood. Therefore, longer-term follow-up studies are needed to track the subsequent development of EF in preterm children, especially those with WM abnormalities. Of particular interest will be the factors that mediate or moderate developmental change within groups of very preterm children.

One key finding from the current results is the apparent absence of executive impairment in the very preterm group without WM abnormality. This finding suggests that early EF impairments displayed by this population may reflect WM pathology rather than the direct effects of prematurity alone. Approximately $50 \%$ of children in this cohort received early intervention support focusing on cognitive, language, and motor skills; so replication of this study is warranted in other population groups.

Neonatal WM abnormalities may relate to later executive impairments in several ways. First, WM abnormalities are likely to result in compromised axonal networks, with particular relevance for EF in the frontal-striatal and corticothalamic systems. Injury to the immature oligodendroglia may additionally impair myelination and thus slow transmission rates in intact surviving axonal networks (Huppi et al., 2001). In addition, WM abnormalities have been shown to be associated with reduction in cortical gray matter volumes (Inder et al., 1999). This association has been hypothesized to result from the deafferentation of the cerebral gray matter with subsequent impairment in synaptogenesis and disorganization of the neuronal networks (Inder et al., 1999). The role of later adaptation within the WM and gray matter throughout childhood following preterm birth has not yet been defined. To fully understand the relationship between neonatal WM abnormalities and cognitive development, longitudinal studies incorporating serial neuroimaging and neuropsychological assessments are required.

Several limitations of the present study need to be acknowledged. The first concerns the lack of a common EF measure two and four years, thus limiting conclusions that can be drawn about continuity and change over time. This difficulty largely reflects the relative absence of EF measures suitable for preschool children that can be used across multiple ages and developmental time points. Many measures, such as the A-not-B task, are suitable from infancy to 2 years of age but lack the complexity required to accu- rately measure working memory and inhibitory control capacities at age 4 years. Recent efforts to develop batteries of preschool executive measures (Carlson, 2005) may prove helpful in addressing this important measurement challenge. A second limitation is the absence of quantitative measures of WM development, such as DTI anisotropy (Counsell et al., 2003; Partridge et al., 2004), which could further specify the nature of the relationship between WM development and executive skills. Despite the absence of this technique, qualitative ratings of WM abnormality are an advancement over the use of cranial ultrasound, which only detects the most severe abnormalities (i.e., IVH and PVL) (Woodward et al., 2006).

In conclusion, we have documented specific deficits in EF in preschool children born very preterm, namely poor inhibitory control and cognitive inflexibility, with evidence of some stability in impaired EF especially among those with mild and moderate-severe WM abnormalities evident on term MRI. Deficits were found even after taking into account background differences (i.e., IQ; SES; and medical background). Utilizing sensitive neuroimaging data, WM abnormalities in the neonatal period were found to relate to later risk of EF difficulties. Such MRI data may be valuable in the identification of specific preterm children at risk for later EF impairment, potentially allowing for earlier and more targeted interventions.

\section{ACKNOWLEDGMENTS}

This study has never been published either electronically or in print. There are no financial or other relationships that could serve as a conflict of interest in the publication of this manuscript. This research was completed as part of a University of Canterbury postdoctoral fellowship with the Canterbury Child Development Research Group. Support for the larger study was obtained from the Neurological Foundation of New Zealand, Lottery Grants Board, Canterbury Medical Research Foundation and the Health Research Council of New Zealand. The authors thank Carole Spencer, Michelle Davey, Jacqueline Knight, and the Canterbury Radiology Group for their assistance with MRI and follow-up data. Also, John Horwood contributed greatly to our analysis of the results with GEE. Most importantly, the authors thank the families who helped with this research.

\section{REFERENCES}

Anderson, P.J., Doyle, L.W., \& The Victorian Infant Collaborative Study Group (2004). Executive functioning in school-aged children who were born very preterm or with extremely low birth weight in the 1990s. Pediatrics, 114, 50-57.

Anderson, P.J., Doyle, L.W., \& The Victorian Infant Collaborative Study Group (2003). Neurobehavioural outcomes of schoolage children who were born very preterm or with extremely low birth weight in the 1990s. Journal of the American Medical Association, 289, 3264-3272.

Assel, M.A., Landry, S.H., Swank, P., Smith, K.E., \& Steelman, L.M. (2003). Precursors to mathematical skills: Examining the roles of visual-spatial skills, executive processes, and parenting factors. Applied Developmental Science, 7, 27-38. 
Bayless, S. \& Stevenson, J. (2007). Executive functions in schoolage children born very prematurely. Early Human Development, 83, 247-254.

Bhutta, A.T., Cleves, M.A., Casey, P.H., Cradock, M.M., \& Anand, K.J.S. (2002). Cognitive and behavioral outcomes of school aged children who were born preterm. Journal of the American Medical Association, 288, 728-737.

Bohm, B., Kats-Salamon, M., Smedler, C., Lagercrants, H., \& Forssberg, H. (2002). Developmental risks and protective factors for influencing cognitive outcome at $51 / 2$ years of age in very low birthweight children. Developmental Medicine and Child Neurology, 44, 508-516.

Caravale, B., Tozzi, C., Albino, B., \& Vicari, S (2005). Cognitive development in low risk preterm infants at 3-4 years of life. Archives of disease in childhood, 90, 474-479.

Carlson, S.M. (2005). Developmentally sensitive measures of executive function in preschool children. Developmental Neuropsychology, 28, 595-616.

Counsell, S.J., Allsop, J.M., Harrison, M.C., Larkman, D.J., Kennea, N.L., Kapellou, O., Cowan, F.M., Hajnal, J.V., Edwards, A.D., \& Rutherford, M.A. (2003). Diffusion-weighted imaging of the brain in preterm infants with focal and diffuse white matter abnormality. Pediatrics, 112, 1-7.

Curtis, W.J., Lindeke, L.L., Georgieff, M.K., \& Nelson, C.A. (2002). Neurobehavioural functioning in neonatal intensive care unit graduates in late childhood and early adolescence. Brain, 125, 1646-1659.

Diamond, A. (1990). The development and neural bases of memory functions as indexed by the $\mathrm{AB}$ and delayed response tasks in human infants and infant monkeys. Annals of the New York Academy of Sciences, 608, 267-317.

Elley, W.B. \& Irving J.C. (2003). Revised socio-economic index for New Zealand. New Zealand Journal of Educational Studies, 38, 3-17.

Espy, K.A., Kaufmann, P.M., McDiarmid, M.D., \& Glisky, M.L. (1999). Executive functioning in preschool children: Performance on A-not-B and other delayed response format tasks. Brain and Cognition, 41, 178-199.

Espy, K.A., Kaufmann, P.M., \& Glisky, M.L. (2001). New procedures to assess executive functions in preschool children. The Clinical Neuropsychologist, 15, 46-58.

Espy, K.A., Stalets, M.M., McDiarmid, M.M., Senn, T.E., Cwik, M.F., \& Hamby, A. (2002). Executive functions in preschool children born preterm: Application of cognitive neuroscience paradigms. Child Neuropsychology, 8, 83-92.

Horwood, L.J., Mogridge, N., \& Darlow, B.A. (1998). Cognitive, educational and behavioural outcomes at 7 to 8 years in a national very low birthweight cohort. Archives of Disease in Childhood: Fetal Neonatal Edition, 79, F12-F20.

Hughes, C., Dunn, J., \& White, A. (1998). Trick or treat? Uneven understanding of mind and emotion and executive dysfunction in "hard-to-manage" preschoolers. Journal of Child Psychology and Psychiatry, 39, 981-994.

Hughes, C. \& Russell, J. (1993). Autistic children's difficulty with mental disengagement from an object: Its implications for theories of autism. Developmental Psychology, 29, 498-510.

Huppi, P.S., Murphy, B., Maier, S.E., Zientara, G.P., Inder, T.E., Barnes, P.D., Kikinis, R., Jolesz, F.A., \& Volpe, J.J. (2001). Microstructural brain development after perinatal cerebral white matter injury assessed by diffusion tensor magnetic resonance imaging. Pediatrics, 107, 445-460.
Inder, T.E., Huppi, P.S., Warfield, S., Kikinis, R., Zientara, G.P., Barnes, P.D., Jolesz, F., \& Volpe, J.J. (1999). Periventricular white matter injury in the premature infant is followed by reduced cerebral cortical gray matter volume at term. Annals of Neurology, 46, 755-760.

Inder, T.E., Warfield, S.K., Wang, H., Huppi, P.S., \& Volpe, J.J. (2005). Abnormal cerebral structure is present at term in premature infants. Pediatrics, 115, 286-294.

Inder, T.E., Wells, S.J., Mogridge, N.B., Spencer, C., \& Volpe, J.J. (2003). Defining the nature of the cerebral abnormalities in the premature infant: A qualitative magnetic resonance imaging study. Journal of Pediatrics, 143, 171-179.

LoBello, S.G. (1991). A short form of the Wechsler Preschool and Primary Scale of Intelligence-Revised. Journal of School Psychology, 29, 229-236.

Luciana, M. (2003). Cognitive development in children born preterm: Implications for theories of brain plasticity following early injury. Development and Psychopathology, 15, 1017-1047.

Luciana, M., Lindeke, L., Georgieff, M., Mills, M., \& Nelson, C.A. (1999). Neurobehavioral evidence for working memory deficits in school aged children with histories of prematurity. Developmental Medicine \& Child Neurology, 41, 521-533.

Matthews, A., Ellis, A.E., \& Nelson, C.A. (1996). Development of preterm and full-term infant ability on $\mathrm{AB}$, recall memory, transparent barrier detour, and means-end tasks. Child Development, 67, 2658-2676.

Ment, L.R., Vohr, B., Katz, A., Scheider, K.C., Westerveld, M., Duncan, C.C., \& Makuch, R.W. (2003). Change in cognitive function over time in very low-birth-weight infants. Journal of the American Medical Association, 289, 705-711.

Partridge, S.C., Mukherjee, P., Henry, R.G., Miller, S.P., Berman, J.I., Jin, H., Lu, Y., Glenn, O.A., Barkovich, A.J., \& Vigneron, D.B. (2004). Diffusion tensor imaging: Serial quantification of white matter tract maturity in premature newborns. Neuroimage, 22, 1302-1314.

Perlman, J.M. (1998). White matter injury in the preterm infant: An important determination of abnormal neurodevelopment outcome. Early Human Development, 53, 99-120.

Rickards, A.L., Kitchen, W.H., Doyle, L.W., \& Kelly, E.A. (1989). Correction of developmental and intelligence test scores for premature birth. Australian Journal of Paediatrics, 25, 127-29.

Ross, G., Boatright, S., Auld, P.A., \& Nass, R. (1996). Specific cognitive abilities in 2-year old children with subependymal and mild intraventricular hemorrhage. Brain and Cognition, $32,1-13$.

Ross, G., Tesman, J., Auld, P.A.M., \& Nass, R. (1992). Effects of subependymal and mild intraventricular lesions on visual attention and memory in premature infants. Developmental Psychology, 28, 1067-1074.

Rushe, T.M., Rifkin, L., Stewart, A.L., Townsend, J.P., Roth, S.C., Wyatt, J.S., \& Murray, R.M. (2001). Neuropsychological outcome at adolescence of very preterm birth and its relation to brain structure. Developmental Medicine \& Child Neurology, 43, 226-233.

Taylor, H.G., Klein, N., Drotar, D., Schluchter, M., \& Hack, M. (2006). Journal of Developmental \& Behavioral Pediatrics, 27, 459-470.

Taylor, H.G., Minich, N., Bangert, B., Filipek, P.A., \& Hack, M. (2004). Long-term neuropsychological outcomes of very low birth weight: Associations with early risks for periventricular brain insults. Journal of the International Neuropsychological Society, 10, 987-1004. 
Taylor, H.G., Minich, N., Klein, N., \& Hack, M. (2004). Longitudinal outcomes of very low birth weight: Neuropsychological findings. Journal of the International Neuropsychological Society, 10, 149-163.

Valkama, A.M., Paakko, E.L.E., Vainionpaa, L.K., Lanning, F.P., Ilkko, E.A., \& Koivisto, M.E. (2000). Magnetic resonance imaging at term and neuromotor outcome in preterm infants. Acta Paediatrica, 89, 348-355.

Vicari, S., Caravale, B., Carlesimo, G.A., Casadei, A.M., \& Allemand, F. (2004). Spatial working memory deficits in children at ages 3-4 who were low birth weight, preterm infants. Neuropsychology, 18, 673-678.

Wechsler, D. (1989). WPPSI-R Manual. New York: Psychological Corporation.

Welsh, M.C. \& Pennington, B.F. (1988). Assessing frontal lobe functioning in children: Views from developmental psychology. Developmental Neuropsychology, 4, 199-230.

Woodward, L.J., Anderson, P.J., Austin, N.C., Howard, K., \& Inder, T.E. (2006). Neonatal MRI to predict neurodevelopmental out- comes in preterm infants. New England Journal of Medicine, 355, 685-694.

Woodward, L.J., Edgin, J.O., Thompson, D., \& Inder, T.E. (2005). Object working memory deficits predicted by early brain injury and development in the preterm infant. Brain, 128 (Pt 11), 2578-2587.

Woodward, L.J., Mogridge, N., Wells, S.W., \& Inder, T.E. (2004). Can neurobehavioural examination predict the presence of cerebral injury in the very low birth weight infant? Journal of Developmental and Behavioral Pediatrics, 25, 326-334.

Zeger, S.L. \& Liang, K. (1992). An overview of methods for the analysis of longitudinal data. Statistical Medicine, 11, 1825-1839.

Zeger, S.L. \& Liang, K. (1986). Longitudinal data analysis for discrete and continuous outcomes. Biometrics, 42, 121-130.

Zelazo, P.D., Reznick, J.S., \& Spinazzola, J. (1998). Representational flexibility and response control in a multistep multilocation search task. Developmental Psychology, 34, 203-214. 